\title{
The Effect of Washing with Water and Detergent on Increasing the Shelf Life of Pepper (Capsicum Annum) on Sale at Rimi and Tarauni Markets of Kano State, Nigeria
}

\author{
${ }^{1}$ Yahaya, S. M*. ${ }^{2}$ Safiya, Y. ${ }^{3}$ Yakasai, M. A. ${ }^{4}$ Sharif, U. ${ }^{5}$ Nuhu, A. A. ${ }^{6}$ Hamisu, A. \\ ${ }^{7}$ Alhassan, K. ${ }^{8}$ Ladan, W. H. ${ }^{9}$ Abba, H. ${ }^{10}$ Safiyanu, I. ${ }^{11}$ Hassan, M. I. ${ }^{12}$ Rahmat, I. I. \\ ${ }^{13}$ Dankaka, A. H. ${ }^{14}$ Labaran, U. ${ }^{15}$ Surayya, L. A.16 Magaji, A. \\ 1,2,4,5,6,7,12,13,14,15, ${ }^{16}$ Department of Biological Sciences \\ Yusuf Maitama Sule University \\ Kano \\ 3,8,9,1011 Department of Biology, \\ Kano University of Science and Technology, \\ Wudil \\ P.M.B. 3244 Kano State \\ Email sanimyahya@gmail.com
}

\begin{abstract}
Sample of pepper was collected from two selected vegetable markets and used to determine the most effective method of increasing shelf life of pepper. In the research two treatment methods used by marketers of vegetables washing with water and detergent were compared. The results showed that five fungal colonies were isolated from pepper samples obtained from the study aeas. The five fungal colonies isolated from the two markets have the following frequency of occurrence A. niger 17 ( 28.3 $\%)$ A. fumigatus $12(23.3 \%)$, R. stolonifer 12 (20.0\%), A. flavus 09(15.05\%) and Mucor spp 08 $(13.3 \%)$. Out of the total 60 fungal colonies isolated in the two markets, more colonies were counted from water wash pepper $37(61.0 \%)$, while lower colony counts were recorded from detergent washed pepper in the two locations 23 ( $38.3 \%)$. It is clear therefore that, this investigation has established fewer fungal colonies counted from detergent washed samples in the two markets is that washing of pepper with detergent is more effective in increasing the shelf life of pepper by removing the surface contaminant micro-organisms.
\end{abstract}

Keywords: Fungal pathogens, Detergent, Pepper, Water, Washing

\section{INTRODUCTION}

A member of the family solanacea Pepper (Capsicum annum) is an important food source and cash especially the northern part of the Nigeria and many countries in the tropics (Alao 2000). The pepper is important in the diet being one of the major source of vitamins A, C, E, B1, B2 and D (Sani and Alao 2006; Ewekeye et al. 2013). In addition potassium, phosphorus, and calcium. Peppers are also obtained from pepper. In many part of the world pepper is used in making vegetable curry, salad etc. in addition pepper has some medicinal values and is used to prepare medications against fever and paralysis (Yahuza and Yahaya 2015). Olawoye 
(2000) reported response of sweet pepper to measures of conservation such as evapotranspiration losses from the soil are reduced, were the plants maximize the use of available moisture, which assist them to reduce dropping of fruits (Ayanda et al. 2013; Yahaya et al., 2015). Nigeria like other tropical countries has availability of fertile land which supports good harvest. Nigeria is among the countries with good record of harvest of vegetables such as pepper, tomato, onions, okra and other vegetables that are grown in various agroecological zones which extend from humid areas from the Southern Nigeria to sub-humid areas in the middle belt and semi-arid/arid areas in the Northern Nigeria . The research conducted by Yahaya et al. (2016) indicated that crop production in Nigeria is seasonal with a glut at the season and then scarcity at off seasons. Losses of produce occur at an alarming rate of $30-50 \%$ every year because of their soft texture they are easily damaged due to poor harvesting, and other post-harvest handling operation such as packaging, transportation and storage (Al-hindi et al. 2011). In the markets damaged peppers are usually mixed with fresh ones which predisposes them to attack by pathogens consequently decreasing their shelf life causing losses of production. Yahaya et al., (2016) showed that the long and complex chain of vegetable marketing between the grower and consumer makes the honest assessment of the losses of crops and vegetables in Nigeria difficult. However, despite all the challenges still there is the need to preserve the vegetables to make it available year round there by reducing global food epidemics. Also results of the previous studies by Alao (2000) has showed that for a country to achieve self-sufficiency in food, there is the need to put in place all strategies for increasing crop production (Mustapha and Yahaya, 2006 ; Kutama et al. 2007). The method of washing pepper is highly important in reduction of contamination after harvest by washing away the surface pathogens which might cause spoilage thereby reducing the post-harvest losses of the commodity (Babalola et al. 2010; Hernandez-Brenes, 2002a). Yahuza and Sani (2015) study on comparism between water washing and detergent washing on reduction of losses of tomato after harvest and found that lower colonies were counted on tomato washed with detergent. Therefore, the present research was an attempt to determine the most suitable washing methods that will increase the shelf life and reduce losses of harvested pepper due to infection by fungal pathogens. Two hypotheses were tested. The first washing pepper with detergent will increase the shelf life of pepper than washing with water. Second isolation and identification of the fungal pathogens that are associated with losses of pepper at Rimi and Tarauni markets of Kano State, Nigeria.

\section{MATERIALS AND METHODS}

\section{Sampling Area}

Rimi Market: - Is situated at Gwale Local Government Area of Kano State. It is among the major vegetables markets in Kano State. However, despite being among the leading markets in Kano State, it lacks good storage facilities. Therefore, marketers store their vegetables either in basket or on rusted basins. They rarely apply chemicals on their vegetables.

Tarauni Market: - Is situated at Tarauni local government area of Kano State. It is also one of big vegetables selling market in Kano State. The market lacks good storage facilities also marketers by spreading on the floor of the store or packed in rusted basins. Markets do not apply chemicals on their stored vegetables.

\section{EXPERIMENTAL PROCEDURES}


The research was done to obtained information on the infection of pepper by fungal pathogens at the two selected markets with the aimed of determining the best treatment method that will increase the shelf life of pepper and reduce postharvest loss. The investigation period was from April, 2021 to June, 2021.

\section{DETERMINATION PATHOGENIC FUNGI CAUSING LOSSES OF PEPPER}

The research was done to determined pathogenic fungi associated with losses of pepper in the market. In the research method similar to the one used Yahuza and Yahaya (2015) and Yahaya et al. (2016) was adopted and used..

\section{SAMPLE COLLECTION}

Six pepper were collected directly from vegetable sellers each at Tarauni and Rimi Markets twice a week and carried to the laboratory at Biology Department, Yusuf Maitama Sule University in polyethylene bags for plating.

\section{SAMPLE HANDLING}

Pepper obtained from Tarauni and Rimi Market was divided into two one half were washed with autoclave water and then allowed to dry. While the other half were washed with detergent water and allowed to dry. Using sterilized clean scalpel a $(2 \mathrm{~mm})$ cut was made on both the water and detergent washed pepper then was placed separately on PDA plate. There after the plates were incubated at $25 \square 27^{\circ} \mathrm{C}$ for three days.

\section{COLONY COUNT AND ITS SUBCULTURE}

The growth of the colonies was monitored on daily basis. The number of colonies that appeared was noted counted and recorded. Each distinct isolates was subcultured into fresh PDA.

\section{COLONY COUNT AND SUBCULTURE}

In each week, growth of fungal colonies was monitored and the number of colonies that appeared was recorded. There after individual colonies were sub cultured into fresh PDA plates and incubated.

\section{PATHOGENICITY TEST}

For pathogenicity tests diseases free pepper was surface sterilized with $10 \%(\mathrm{v} / \mathrm{v})$ sodium hypochlorite solution the pepper was then washed three times under changes of running tap and water and left on laboratory bench to dry. The pepper was then streaked with fungal hyphae. For the controls the pepper was streaked with drops of sterile distilled water. The experimental set up were then left on the bench. On the fourth day using clean and sterilized forceps portions was removed from the infected areas and mounted on freshly prepared plates containing PDA and incubated.

\section{MICROSCOPIC EXAMINATION}

For the microscopic examination using clean and sterilized inoculating loop a fungal mycelium was streak on a clean glass slide. A drop of indicator cotton blue lacto phenol was placed on the fungal mycelium then cover slip was gently placed. The prepared slide was then observed under microscope at magnification of $x 10$ and $x 40$. The morphological characteristics of isolated fungal colonies was determined following the procedure developed by Dorothea, et al. (1976). Photographs of the isolated colonies was taken from microscope using camera attached to the microscope.

\section{STATISTICAL ANALYSIS}


One way analysis of variance (ANOVA) was used to analyzed the data were all the differences among the means was determined at $\mathrm{P} \leq 0.05$ for significance.

\section{RESULTS}

At the end of the research 60 fungal colonies uwere isolated counted and recorded from the two treatments. Fungal colonies that were used during the pathogenicity test were similar to ones isolated at the end of the test. Water washed pepper from both Rimi and Tarauni showed a colony count of $37(62.0 \%)$. In the detergent washed pepper from both the two markets a colony count of $23(38.3 \%)$. Four fungal colonies were confirmed (Table 6), A. niger, $A$. fumigatus, A. flavus, R. stolonifer and Mucor. The following composition was determine from the identified five fungal colonies A. niger, 17(28.3\%), A. fumigatus 14 (23.3\%), A. flavus 09 ( $15.0 \%$ ), R. stolonifer 12 (20.0\%) and Mucor 08 (13.3\%).

\section{Influence of isolation Days on the Number of Isolated Colonies from the two markets}

No significant difference was found between the number of colonies isolated from the two markets on Monday and Thursday.

It is clear that high number of colonies were counted on Thursday $31(52.0 \%)$ and while least colonies were counted on Monday 29 (48.0\%) during the period of study (Table 1).

Table 1: Total number of fungal colonies counted from the two treatment in the two locations

\begin{tabular}{lccccc}
\hline Location & Rimi & Tarauni & Total & Mean & $\%$ abundance \\
\hline Monday & 13 & 16 & 29 & 14.5 & 48.00 \\
Thursday & 21 & 10 & 31 & 15.5 & 52.00 \\
Total & 34 & 26 & 60 & 30.0 & 100 \\
\hline
\end{tabular}

Effect of location on the number of fungal colonies counted from the two treatments in the two locations

Although more colonies were counted from water wash and detergent wash pepper obtained from Rimi $34(57.0 \%)$ as compare to water wash and detergent wash pepper obtained from Tarauni $26(43.0 \%)$ but the differences was not significant. However, with regard to the treatment methods more colonies were counted on water wash pepper $37(61.0 \%)$ while the detergent wash pepper has the least counted colonies $23(38.0 \%)$ during the period of study (Table 2).

Table 2: Fungal colonies counted from the two treatments in the two selected markets

\begin{tabular}{lccccc}
\hline Location & Water washed & Detergent washed & Total & Mean & $\%$ \\
\hline Rimi & 21 & 13 & 34 & 17 & 57.0 \\
Tarauni & 16 & 10 & 26 & 13 & 43.0 \\
Total & $37(61.0 \%)$ & $23(38.3 \%)$ & 60 & 30 & 100 \\
\hline
\end{tabular}

\section{Isolated fungal colonies from water wash pepper in the two selected markets}

Five colonies were obtained as fungal pathogens concerned with the losses of water wash pepper in the two selected markets. The composition of the isolated fungal colonies was $A$. niger was the most commonly occurring colony and has the percentage occurrence of 10 $(27.0 \%)$, A. fumigatus $09(24.32 \%)$, R. stolonifer $08(21.62 \%)$ while A. flavus and Mucor are the lowest occurring colonies each with 05 (13.0\%) (Table 3). 
Table 3; Total number of fungal colonies isolated from water washed pepper collected from the two selected markets

\begin{tabular}{cccccc}
\hline Colonies & $\begin{array}{c}\text { water washed } \\
\text { Rimi }\end{array}$ & $\begin{array}{c}\text { water washed } \\
\text { Tarauni }\end{array}$ & Total & Mean & \% abundance \\
\hline A. niger & 08 & 02 & 10 & 5 & 27.0 \\
A. flavus & 03 & 02 & 05 & 2.5 & 13.00 \\
A. fumigatus & 05 & 04 & 09 & 4.5 & 24.32 \\
R. Stolonifer & 06 & 02 & 08 & 4 & 21.62 \\
Mucor & 02 & 03 & 05 & 2.5 & 13.00 \\
Total & 24 & 13 & 37 & 18.5 & 98.94 \\
\hline
\end{tabular}

Fungal colonies counted from Detergent washed pepper in the two selected markets Five fungal colonies were counted and identified as the fungal pathogens concerned with the losses of water washed pepper in the two selected markets. The composition of the counted fungal colonies was found as $A$. niger as the most commonly occurring colony with frequency of occurrence of $07(30.40 \%)$, A. fumigatus $05(22.0 \%)$ while R. stolonifer and A. flavus have the same frequency of occurrence of $04(17.3 \%)$ while Mucor was the lowest occurring colony with $03(13.0 \%)$ (Table 4).

Table 4: Total number of colonies counted from detergent washed pepper obtained from the two locations

\begin{tabular}{lcccccc}
\hline Colonies & $\begin{array}{c}\text { Detergent washed } \\
\text { Rimi }\end{array}$ & $\begin{array}{c}\text { Detergent washed Total } \\
\text { Tarauni }\end{array}$ & Mean & $\%$ abundance \\
\hline A. niger & 05 & 02 & 07 & 3.5 & 30.4 \\
A. flavus & 03 & 01 & 04 & 2 & 17.3 \\
A. fumigatus & 03 & 02 & 05 & 2.5 & 22.0 \\
R. Stolonifer & 02 & 02 & 04 & 2 & 17.3 \\
Mucor & - & 03 & 03 & 1.5 & 13.0 \\
Total & 13 & 10 & 23 & 11.5 & 100 \\
\hline
\end{tabular}

Comparism of the Number of colonies obtained from both the two treatments in both Rimi and Tarauni markets

The results of the research indicated that $A$. niger was the highest occurring colony in the both Rimi and Tarauni markets with colony counted as 17 (28.3\%) followed by A. fumigatus with $14(23.3 \%)$, R. stolonifer with $12(20.0 \%)$. Then A. flavus 09 (15.0\%), while Mucor was the lowest occurring fungal colony in the two selected markets 08 (13.0\%) (Table 5).

Table 5: Comparism of the number of fungal colonies obtained from the two treatments in the two selected markets

\begin{tabular}{|c|c|c|c|c|c|}
\hline 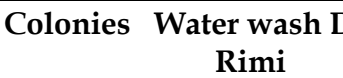 & $\begin{array}{l}\text { ergent } w \\
\text { Rimi }\end{array}$ & $\begin{array}{l}\text { ed Water wa } \\
\text { Tarauni }\end{array}$ & $\begin{array}{l}\text { sh Deterger } \\
\text { Tarauni }\end{array}$ & d Tota & 1 Mean $\%$ \\
\hline A. niger & 05 & 02 & 02 & 17 & $8.5 \quad 28.3$ \\
\hline A. flavus & 03 & 02 & 01 & 09 & 4.515 .0 \\
\hline A. fumigatus 05 & 03 & 04 & 02 & 14 & $7 \quad 23.3$ \\
\hline R. Stolonifer 06 & 02 & 02 & 02 & 12 & $6 \quad 20.0$ \\
\hline Mucor & - & 03 & 03 & 08 & 13.3 \\
\hline Total & 13 & 13 & 10 & 60 & 3099.9 \\
\hline
\end{tabular}


Table 6: Shows morphological and colonial characteristics of identified fungal spp from water washed and Detergent washed pepper collected from Rimi and Tarauni markets

\begin{tabular}{llll}
$\mathrm{s} / \mathrm{n}$ & Appearance on PDA & Morphological characteristics & Organism Identified \\
\hline
\end{tabular}

1. The colony grows rapidly Many mycelia, conidia Aspergillus niger

black colour reverse is and conidiophores black,

is colourless or yellow later spherical to oval head of conidia

black. is globose splitting into columns.

2. Colony grow fast

Velvet in texture, white at

First later blue green

to dark green. The lower is

part is colourless or yellow
Conidiophores was smooth greenish

upward to form apical flask shaped

vesicle. Conidia green mass and,

globose, rough, mainly2.5-3m

in diameter.

3. Colony grow flat granular, Head of conidia typically radiate, with radial grooves, later form loose columns initially yellow but (mostly 300-400um in diameter), becoming bright to dark biseriate with some heads having Yellow-green . Philalides borne on the vesicle.

4. Colony grows very fast white cottony initially, later brownish black at maturity.

\author{
The stolons creeping, and recurve to the \\ substrate. as hyphae, which are \\ strongly raised and far from \\ the substrate. .
}

\section{ACKNOWLEDGEMENT}

The research was carried out at the Department of Biological Sciences Yusuf Maitama Sule University Kano during my one year sabbatical 2021.

\section{DISCUSSION}

The study showed that a total of 60 fungal colonies were isolated from the two treatments. Out of which five fungal species comprising Aspergillus niger, A. fumigatus, A. flavus and Rhizopus stolonifer were obtained from the two markets. More colonies were counted from water washed pepper than detergent washed pepper in the two markets. In addition high number of fungal colonies were counted from pepper sample collected from Rimi market than pepper sample collected from Tarauni market. More colonies were counted from water wash sample of both the two markets $37(61.0 \%)$, than detergent wash $23(38.3 \%)$. (Table 2). Colonies counted from water wash pepper of Rimi has more colonies than $24(64.86 \%)$ than colonies counted from Tarauni which were wash with water 13 (35.13\%) this is followed by A. fumigatus $5(22.0 \%)$.

Total number of $13(56.5 \%)$ fungal colonies was isolated from the detergent washed pepper sampled from Rimi market. While 10 (43.47\%) were isolated from detergent wash pepper collected from Tarauni market (Table 2 and 4 ). Identical fungal colonies were isolated from water wash pepper from the two markets they consist of Aspergillus niger, Aspergillus fumigatus, Aspergillus flavus, Rhizopus stolonifer and Mucor. Out of the colonies isolated A. niger was the highest occurring colony $17(28.3 \%)$ followed by A. fumigatus $14(23.3 \%)$ and $R$. stolonifer $6(20.0 \%)$ and A. flavus $9(15.0 \%)$ while the least occurring colony was Mucor 8 $(13.3 \%)$. Similarly, colonies isolated from detergent wash pepper in the two markets were also identical to the colonies isolated from water wash pepper. Out of the colonies A. niger was 
the highest occurring colony with $7(30.4 \%)$ while A. flavus and R. stolonifer have same frequency of occurrence each with 4 (17.3\%). the least occurring colony was Mucor $3(13.0 \%)$. (Table 4). The result of the present study could be compare with the results obtained by Yahuza and Yahaya (2015) who investigated the effect of washing with water and detergent on reduction of postharvest losses of tomato on sale at Yankaba and Tarauni markets of Kano state, Nigeria and found that less fungal colonies were isolated from detergent wash tomato than water wash tomato. The finding is also similar to the results obtained by Hayatu (2000) who isolated A. niger, A. flavus, R. stolonifer and Mucor spp from sample of pepper collected from Nassarawa Local Government of Kano State, Nigeria. The finding of this research could also be related to the result of Kuku et al. (1980) who studied mould deterioration of some vegetables in northern Nigeria and found that $60 \%$ of losses in tomato and pepper was attributed to the activities of $A$. niger while A. fumigatus and Rhizopus stolonifer accounted for $30 \%$ and $10 \%$ respectively.

Therefore, from the result of the study it can be concluded that higher number of fungal colonies was isolated from water wash pepper than detergent wash pepper. Therefore, this is an indication that washing pepper with detergent is more effective in reducing fungal colonies from the surface of the pepper which consequently reduces postharvest losses of the pepper. Therefore, it is recommended that washing of pepper with detergent after harvest should be encouraged in the market to increase the shelf life of the produce.

\section{REFERENCES}

Alao SEL (2000). The importance of post-harvest loss prevention. Paper presented at graduation ceremony of school of food storage technology. Nigerian Stored Products Research Institute, Kano. Pp 1-10.

Al-Hindi R.R, Al-Najada A.R, Mohamed S.A. (2011). Isolation and identification of some fruit spoilage fungi: Screening of plant cell wall degrading enzymes. Afr. J. Microbiol. Res.

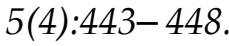

Ayanda, O. Ajayi, A. A., Olasehinde, G. I. (2013). Isolation characteristic and extracellular enymes detection of microbial isolates. International journal of Biology, chemistry Science 7(2): 641-648.

Babalola, D. A. Makinde, Y. O., Osmonanona, B. T., and Oyekanmi, M. O.,(2010).

Determination of postharvest losses of tomato production; a case study of imeko $\square$ Afon Local Government Area Ogun State. Acta Satech 3 14-18.

Dorothea, F, Ronald, J. and Ronald, C.B. (1976). A Colour Atlas of Pathogenic Fungi. Wolfe Medical Publication Ltd. Pp $12 \square 53$.

Ewekeye, T. S., Okey, O. A., Quadri, A. I., Isikalu, A. O., Umemwaniri, M. O., and Durosinmi, M. L. (2013). Studies on Harvest Deterioration of some Fruits and Vegetables in selected markets in Lagos State, Nigeria. American Journal of Research Communication 1(10) 209-223. Wicker asket. SWJ. 2, 38-39.

Hayatu, M. (2000). Post Harvest Physiological Studies of Some Selected Members of Family Solanaceae. M. Sc thesis(unpublished). Department of Biological Sciences, Bayero University, Kano. Pp $2 \square 25$.

Kutama, A. S. Aliyu, B. S and Mohammed, I. (2007). Fungal pathogen associated with tomato wicker basket. SWJ. 2 38-39.

Kuku, F. O., Akano, D. A., Olarewaju, T.O. and Oyeniran, J.O. (1980). Mould Deterioration on Vegetables. NSPRI Technical Report. No. 8, 1985 Annual Report. Pp $89 \square 94$. 
Mustapha, Y. Yahaya, S.M. (2006). Isolation and Identification of Post-harvest fungi of Tomato (L. esculentum) and Pepper (Capsicum annum) Sample from selected Irrigated sites in Kano. Biological and Environmental Science Journal for the Tropics 3: 139-141.

Sani M.Y, Alao, S.E.A. (2006). Assessment of post-harvest fungi of Tomato (Lycopersicon esculentum) and Pepper (capsicum annum) from selected irrigated areas of Kano State. Journal of Bioscience 2: 53-56.

Yahaya, S.M. Fagwalawa, L.D. Ali, M.U. Lawan M, Mahmud S. (2015). Isolation and Identification of Pathogenic Fungi Causing Deterioration of Lettuce Plant (Lactuca sativa) A Case Study of Yankaba and Sharada Vegetables Markets. Journal of Plant Science \& Research 3(1)

Yahaya, S.M., Fagwalawa, L. D., Ali, M.U., Lawan, M., Mahmud, S. ( 2016). Identification of Pathogenic Fungi Causing Deterioration of Lettuce Plant (Lactuca sativa). Case Study of Yankaba and Sharada Vegetables Markets. Journal of Plant Science and Research 3(1)

Yahuza, A. and Yahaya, S. M. (2015). Comparism between Water washing and Detergent Washing on reduction of Postharvest losses of Tomato 9Lycopersicon esculentum). Indian Journal of Plant Science. ISSN 2319-3824 494):22-29. 